\title{
Effect of Salicylic Acid and Potassium Application on Yield and Grain Nutritional Quality of Wheat under Drought Stress Condition
}

\author{
M. SAFAR-NoORI ${ }^{1}$, D.V.M. Assaha ${ }^{2}$ and H. SANEOKA ${ }^{1 *}$ \\ ${ }^{1}$ Graduate School of Biosphere Science, Hiroshima University, 1-4-4 Kagamiyama, \\ Higashi-Hiroshima, 739-8528, Japan \\ ${ }^{2}$ Department of Biology, Sultan Qaboos University, Muscat, Oman \\ (Received 30 October 2017; Accepted 5 February 2018; \\ Communicated by I. Molnár)
}

\begin{abstract}
Drought stress severely reduces wheat productivity and affects grain quality. In this study the effects of combined application of salicylic acid (SA) and potassium (K) on yield and grain quality of wheat under drought stress condition was investigated. Winter wheat cultivar Minaminokaori was grown in pots in a greenhouse, and subjected to 3 levels of K $(50,100$ and $\left.200 \mathrm{~kg} \mathrm{ha}^{-1}\right)$ fertilizer applications. The plants were foliar sprayed with SA $(0.7 \mathrm{mM})$ at heading stage, and then imposed to the drought stress until grain maturity. Drought stress decreased grain yield by $41.1 \%$, starch content by $10.2 \%$ and water-soluble pentosan content by $3.5 \%$ in comparison to well-irrigated control. However, grain crude protein content, total pentosan content and phytate phosphorus content were increased by $33.0 \%, 17.9 \%$, and $13.4 \%$ respectively. Under the same drought condition, the application of combined SA and high $\mathrm{K}$ levels has increased grain yield (13.3\%), starch (12.2\%) and water-soluble pentosan content $(20.3 \%)$ compared to SA-untreated with low level of $\mathrm{K}$ fertilizer. In addition, SA application decreased the percentage of phytate phosphorus to total phosphorus under drought stress. These results suggested that combined treatment of SA foliar application and a higher doses of $\mathrm{K}$ fertilizer can partially improve wheat productivity, grain nutritional quality, particularly water-soluble pentosan that influences the bread-making quality, without increasing the anti-nutrient component phytate under drought stress condition.
\end{abstract}

Keywords: drought stress, grain quality, pentosan, phytate P, salicylic acid, wheat

\section{Introduction}

Drought stress negatively affects plant growth and productivity, and threatens successful crop production more than other environmental stresses (Zhu 2002). Approximately 32\% of wheat fields suffer from several types of drought stresses throughout their growth period in developing countries (Morris et al. 1991). Drought stress at anthesis stage decreases pollination and therefore, number of grains per spike and grain yield is reduced (Ashraf 1998).

\footnotetext{
*Corresponding author; E-mail: saneoka@hiroshima-u.ac.jp
} 
Potassium (K) can play effective roles in the physiological processes of photosynthesis, formation of carbohydrates and protein, transportation of water and nutrients, nitrogen (N) utilization, and stimulation of early growth in plants (Daniel et al. 2016; Lakudzala 2013). It controls stomata opening and enhances enzyme activation in plants, therefore it improves crop productivity (Yawson et al. 2011). Application of K enhances transportation of water, nutrients, and carbohydrates in plant tissue (De La Guardia and Benlloch 1980). Under drought stress condition, leaf stomata fail to function actively in K-deficient plants, and subsequently, cause excessive water loss (Egilla et al. 2005).

Salicylic acid (SA) is a plant growth regulator which enhances plant defense against various biotic and abiotic stresses through morphological, biochemical, and physiological mechanisms (War et al. 2011). SA alleviates the detrimental effects of different abiotic stresses by enhancing the internal level of various hormones in plants (Sakhabutdinova et al. 2003). Waseem et al. (2006) and Arfan et al. (2007) reported that SA is a conservative compound of some biotic and abiotic stresses and it functions primarily as a molecular signal for the adjustment of plants under abiotic stress conditions. According to Gunes et al. (2005) plant growth, transpiration rates, stomatal regulation and photosynthetic processes, ion uptake, and transport, are regulated by SA.

Pentosan is a major fiber component of the non-starch polysaccharides in cereal, commonly referred to as flour gum or hemicellulose. Pentosan is an important component of bread dough in which they bind water and contribute to the formation of viscous dough (Buksa et al. 2010). Water-soluble pentosan has a positive effect on the bread-making quality of wheat flour (Courtin and Delcour 2002). Unlike pentosan, phytate is known as an anti-nutritional factor, because it binds with proteins and some important micronutrients, such as $\mathrm{Fe}$ and $\mathrm{Zn}$, and significantly reduces their availability (Raboy 2001). Although the adverse effects of drought on the contents of these compounds have been studied (Rakszegi et al. 2014; Patel and Singh 1998), the mechanism of improvement of these components under drought stress condition has not been examined.

Wheat is an important human food, and contributes to the world food security. It provides about $20 \%$ of the total dietary calories and proteins world-wide (Shiferaw et al. 2013). It is well evident that environmental change threatens all human life by affecting crop productivity. We aimed to investigate whether productivity and grain quality of wheat can be improved by combined K and SA application. Therefore, the present experiment was designed to evaluate the combined effects of SA and K on productivity, grain starch, crude protein, total pentosan, water-soluble pentosan, phytate $\mathrm{P}$ and mineral content of wheat under drought stress condition.

\section{Materials and Methods}

\section{Plant material and growth conditions}

This study was conducted in a vinyl greenhouse in the Graduate School of Biosphere Science, Hiroshima University with natural sunlight and temperature. A commonly grown wheat cultivar in Japan, Minaminokaori, was used in this study. Pots (9 litter capacity) 
were used and filled with $8.25 \mathrm{~kg}$ of a mixture of regosol, vermiculite, and peat moss $(2: 1: 1 \mathrm{v} / \mathrm{v})$. The chemical composition of this mixture was: $0.14 \%$ total $\mathrm{N}, 4.85 \mathrm{mg} \mathrm{kg}-1$ available $\mathrm{P}$, and $65.73 \mathrm{mg} \mathrm{kg}^{-1}$ available $\mathrm{K}$. Meanwhile dolomitic calcium magnesium carbonite $\left(4.9 \mathrm{~g} \mathrm{pot}^{-1}\right)$ was mixed with the soil to adjust the $\mathrm{pH}\left(\mathrm{H}_{2} \mathrm{O}\right)$ to 6.5. Potassium (K) treatment comprised of 3 levels: $\mathrm{K}_{1}\left(50 \mathrm{~kg} \mathrm{ha}^{-1}\right), \mathrm{K}_{2}\left(100 \mathrm{~kg} \mathrm{ha}^{-1}\right)$ and $\mathrm{K}_{3}(200 \mathrm{~kg}$ $\left.\mathrm{ha}^{-1}\right)$. They were applied in pots, as $\mathrm{K}_{1}\left(0.49 \mathrm{~g} \mathrm{pot}^{-1}\right), \mathrm{K}_{2}\left(0.98 \mathrm{~g} \mathrm{pot}^{-1}\right)$, and $\mathrm{K}_{3}(1.96 \mathrm{~g}$ pot $^{-1}$ ) as potassium sulfate. All 3 doses of $\mathrm{K}$ fertilizer and $4.32 \mathrm{~g} \mathrm{pot}^{-1}$ of single superphosphate were applied to the soil after pot preparation. $\mathrm{N}$ fertilization $\left(2.13 \mathrm{~g}\right.$ urea pot $\left.^{-1}\right)$ was carried out in 3 split doses, half dose of urea was applied prior to transplanting, and the remaining second and third splits of urea were applied at tillering and anthesis stages, respectively. Ten-day-old seedlings were transplanted into the pots (one plant per pot) and arranged in a randomized complete block design with 4 replicates. The plants were irrigated regularly with the tap water. Salicylic acid (SA; 2-hydroxybenzoic acid) treatment was carried out at the heading stage for both well-irrigated and drought stressed plants. SA thoroughly dissolved in heated distilled water, and $2 \mathrm{ml}$ of $0.7 \mathrm{mM}$ SA solution was carefully sprayed on wheat leaves using wheaton reagent sprayer (Cole-Parmer). To compare the effect of SA treatment with those of non-treated plants, one set of plants was foliar sprayed with $2 \mathrm{ml}$ of distilled water per plant (SA-untreated).

Drought treatments consisting of well-irrigated and drought stress conditions were imposed at the anthesis stage, by adjusting the soil water content to $18.0 \%$ and $9.0 \%$ for the well-irrigated, and drought stress conditions, respectively, using Time Domain Reflectometry (TDR-341F model, Fujiwara, Japan) digital moisture meter. The moisture content was regularly monitored with the TDR. The drought stress continued for 45 days until the crop reached harvesting maturity.

\section{Grain yield}

Spikes were collected from each plant at harvesting maturity and dried at $80{ }^{\circ} \mathrm{C}$ for 72 hours. They were threshed manually, and grain yield was recorded per plant and expressed in g per plant.

\section{Determination of starch, protein, total pentosan and water soluble pentosan content}

For the determination of grain starch percentage, $80 \%$ ethanol was added to the powdered samples to remove sugars and then starch was extracted with perchloric acid. Anthrone reagent was added to the tubes containing extracted samples and then heated in boiling water bath. The absorbance was measured at $630 \mathrm{~nm}$ (Nag 2016). Crude protein was calculated by multiplying the total $\mathrm{N}$ content by 5.47 (Fujihara et al. 2008) and the content is expressed as percent crude protein in dry weight. Total pentosan was measured following the orcinol- $\mathrm{HCl}$ method where, finely ground samples were hydrolyzed with $2 \mathrm{~N} \mathrm{HCl}$ in boiling water for 2.5 hours, and centrifuged. Then a specific amount of supernatant was transferred to new test tubes and reaction reagents $\left(\mathrm{FeCl}_{3}\right.$ and Orcinol) were added and vortexed. The tubes were heated in boiling water for 30 minutes, cooled, and the absorbance was measured using a spectrophotometer. Water-soluble pentosan was extracted by 
hydrolyzing powdered samples in distilled water with shaking for 2 hours at $30{ }^{\circ} \mathrm{C}$. Then, $4 \mathrm{~N} \mathrm{HCl}$ was added to the aliquots of the supernatant and placed in boiling water for 2 hours, and allowed to cool, and water-soluble pentosan was estimated by a spectrophotometer, using $\mathrm{FeCl}_{3}$-orcinol reagents (Hashimoto et al. 1986). Pentosans content is expressed as mg per $g$ dry weight of grains.

\section{Determination of phytate phosphorus (Phy-P)}

Phy-P was measured following the method described by Raboy and Dickinson (1984). Portions of powdered samples were extracted in extraction media $(0.2 \mathrm{M} \mathrm{HCl}: 10 \%$ $\mathrm{Na}_{2} \mathrm{SO}_{4}$ ) overnight at $4{ }^{\circ} \mathrm{C}$ with shaking. Extracts were centrifuged, and Phy-P was obtained as a ferric precipitate and assayed for $\mathrm{P}$ using ammonium molybdate reaction reagent. The content is expressed as mg Phy-P in g dry weight of grains.

\section{Determination of grain mineral contents}

Samples of mature seeds were ground finely with a vibrating sample mill (TI-100, Heiko, Japan) and the contents of grain minerals were measured. Finely ground samples were digested by $\mathrm{H}_{2} \mathrm{SO}_{4} / \mathrm{H}_{2} \mathrm{O}_{2}(2: 1, \mathrm{v} / \mathrm{v})$ and the $\mathrm{K}$ content was measured using a flame photometer (ANA 135, Tokyo Photoelectric, Tokyo, Japan). Ca, Mg, and $\mathrm{Zn}$ were measured by an atomic absorption flame emission spectrophotometer (AA-6200, Shimadzu, Japan). The total $\mathrm{P}$ was determined by a UV-Spectrophotometer (U-3310, Hitachi Co. Ltd. Tokyo, Japan) following the molybdenum reaction solution method suggested by Chen et al. (1956). Inorganic Phosphorus (Pi) was extracted in trichloroacetic acid (12.5\%)+ $\mathrm{MgCl}_{2}(2 \mathrm{mmol} / \mathrm{l})$ while stirring overnight, and Pi was measured colorimetrically (Raboy and Dickinson 1984). The total $\mathrm{N}$ was measured using the Kjeldahl method after sample digestion with concentrated $\mathrm{H}_{2} \mathrm{SO}_{4}$ and $\mathrm{H}_{2} \mathrm{O}_{2}$. All mineral contents are expressed as amount of mineral per $\mathrm{g}$ dry weight of grains, considering $11 \%$ moisture.

\section{Statistical analysis}

All obtained data were subjected to statistical analysis of variance (ANOVA) using the SPSS statistical package version 22 (IBM Inc. USA), and treatment means were compared using the Duncan Multiple Range Test at $\mathrm{p}=0.05$.

\section{Results}

\section{Grain yield}

Grain yield was significantly decreased under drought stress condition. Application of SA resulted in a higher grain yield under well-irrigated as well as drought stress conditions compared to SA-untreated plants (Table S1*). A higher dose of $\mathrm{K}$ fertilization was more 
effective under well-irrigated condition, while under drought stress it resulted in a slight increase in grain yield. $\mathrm{K}_{3}$ treatment increased grain yield in SA treated plants under both well-irrigated and drought stress conditions. The lowest grain yield was observed with $\mathrm{K}_{1}$ treatment in SA-untreated plants under drought stress condition. Combination of SA $+\mathrm{K}_{3}$ treatments increased grain yield by 14.2 and $13.3 \%$ compared to SA-untreated and $\mathrm{K}_{1}$ treatment, under both well-irrigated and drought stress conditions, respectively.

\section{Grain starch, crude protein, pentosan and water soluble pentosan content}

Drought stress reduced the starch content under all levels of K treatments, and the reduction was greater in SA-untreated plants (Table S1). Application of SA enhanced grain starch content under drought stress condition. Different levels of $\mathrm{K}$ fertilization did not affect grain starch content significantly. The lowest starch content was observed in SAuntreated plants of $\mathrm{K}_{1}$ treatment, while combined SA and $\mathrm{K}_{3}$ treatments resulted in a higher starch content. $\mathrm{SA}+\mathrm{K}_{3}$ treatments increased grain starch content by $12.2 \%$ under drought stress condition, compared to SA-untreated $+\mathrm{K}_{1}$ treatments. Crude protein content was recorded higher under drought stress condition. Application of SA did not affect grain crude protein content under well-irrigated condition, however it significantly increased crude protein content under drought stress condition (Table S1). Different levels of $\mathrm{K}$ fertilization did not significantly affect grain crude protein content under well-irrigated as well as drought stress conditions. Application of SA in combination with $\mathrm{K}_{3}$ treatment significantly increased grain crude protein under drought stress condition. The highest level of crude protein was observed under drought stress condition in SA treated plants with $\mathrm{K}_{3}$ treatment. $\mathrm{SA}+\mathrm{K}_{3}$ treatments increased grain crude protein content by 9.7\% compared to SA-untreated $+\mathrm{K}_{1}$ treatments under drought stress condition. Total pentosan content was significantly increased under drought stress compared to well-irrigated condition irrespective of SA treatment and various levels of K fertilization. SA application alone did not affect the total pentosan content under drought stress condition, while combined SA and $\mathrm{K}_{3}$ treatments slightly increased grain total pentosan content. $\mathrm{SA}+\mathrm{K}_{3}$ treatments increased grain total pentosan content by $7.55 \%$ compared to SAuntreated $+\mathrm{K}_{1}$ treatments under drought stress condition (Table S1). Water-soluble pentosan content was slightly reduced under drought stress condition in SA-untreated plants where a low $\mathrm{K}$ fertilizer was also applied. Application of SA alone did not affect grain water-soluble pentosan content, while $\mathrm{K}_{3}$ treatment slightly enhanced water-soluble pentosan content under both well-irrigated and drought stress conditions (Table S1). A higher value of water-soluble pentosan was observed with combined SA and $\mathrm{K}_{3}$ treatments. $\mathrm{SA}+\mathrm{K}_{3}$ treatments increased grain water-soluble pentosan by $20.3 \%$ compared to SAuntreated $+\mathrm{K}_{1}$ treatments under drought stress condition.

\section{Phytate phosphorus (Phy-P) content}

Drought stress increased grain Phy-P content by $13.4 \%$ compared to well-irrigated condition (Table S1). $\mathrm{K}_{3}$ treatment recoded the highest Phy-P content under drought stress 
condition. SA application did not affect grain Phy-P content, significantly. However, combined SA and K treatments influenced the percentage of Phy-P to total P. The percentage of Phy-P to total $\mathrm{P}$ content was remarkably decreased by $\mathrm{SA}+\mathrm{K}_{3}$ treatments compared to SA-untreated under drought stress condition.

\section{Grain minerals content}

Grain mineral content was significantly influenced by SA and K application under drought stress condition (Table S2). The total K content in grains was higher in SA-treated plants under drought stress condition, while the lowest K content was observed under well-irrigated condition irrespective of SA and $\mathrm{K}$ treatments. The higher level of $\mathrm{K}\left(\mathrm{K}_{3}\right)$ did not enhance $\mathrm{K}$ content in SA untreated plants under well-irrigated condition, but SA application with $\mathrm{K}_{3}$ and $\mathrm{K}_{2}$ treatments significantly increased $\mathrm{K}$ content under drought stress condition. Combined SA and $\mathrm{K}_{3}$ treatments resulted in the highest $\mathrm{K}$ content under drought stress condition. With respect to $\mathrm{N}$, drought stress significantly enhanced grain $\mathrm{N}$ content. Higher total $\mathrm{N}$ content was observed in SA-treated plants under drought stress condition. Although various levels of $\mathrm{K}$ did not significantly affect total $\mathrm{N}$ content under well-irrigated condition, the combined SA and $\mathrm{K}_{3}$ treatments resulted in a higher value of total $\mathrm{N}$ content under drought stress condition compared to SA-untreated. Drought stress significantly increased grain P content. Different levels of $\mathrm{K}$ fertilization did not significantly affect grain $\mathrm{P}$ content, however SA-treated plants recorded slightly higher grain $\mathrm{P}$ content under well-irrigated as well as drought stress conditions. Drought stress increased grain inorganic phosphorus (Pi) content. Different levels of K fertilization did not significantly influence grain Pi content. While, SA application slightly increased grain Pi content particularly when it combined with $\mathrm{K}_{3}$ treatment. Grain $\mathrm{Mg}$ content was higher under drought stress condition irrespective of SA and $\mathrm{K}$ treatments. The combined SA and $\mathrm{K}_{3}$ treatments recorded higher value of $\mathrm{Mg}$ content, however the difference was statistically insignificant. Grain Ca content increased under drought stress condition. $\mathrm{K}_{2}$ and $\mathrm{K}_{3}$ treatments remarkably increased grain $\mathrm{Ca}$ content, and the highest $\mathrm{Ca}$ content was obtained under $\mathrm{SA}+\mathrm{K}_{3}$ and $\mathrm{SA}+\mathrm{K}_{2}$ treatments. Zn content was higher under drought stress condition irrespective of $\mathrm{SA}$ and $\mathrm{K}$ treatments. In general, $\mathrm{SA}+\mathrm{K}_{3}$ treatments increased grain $\mathrm{K}, \mathrm{N}, \mathrm{P}, \mathrm{Pi}, \mathrm{Mg}, \mathrm{Ca}$ and $\mathrm{Zn}$ contents of grains by 11.1, 9.6, 8.9, 15.3, 11.1, 42.3 and 4.0\%, respectively, compared to $\mathrm{SA}$-untrated $+\mathrm{K}_{1}$ treatments under drought stress condition.

\section{Discussion}

Application of SA either through seed soaking, adding to the nutrient solution, irrigating, or spraying was found to improve abiotic stress tolerance mechanisms in plants under environmental stress conditions (Gondor et al. 2016; Horvath et al. 2007; Khan et al. 2015; War et al. 2011). Foliar application as spraying SA on leaves might be an appropriate method to attenuate the adverse effects of post-anthesis drought stress. Potassium (K) is an influential macro-nutrient which plays a key role in improving plant water status, stomatal movements, enzyme activity, osmoregulation and membrane stability that may 
help the plants to tolerate the adverse effect of drought stress (Ahmad et al. 2014; Jatav et al. 2014; Erel et al. 2015). In the present study the combined effect of SA foliar application and various levels of $\mathrm{K}$ fertilization on wheat productivity and grain quality was evaluated. The results of present study indicated that drought stress at anthesis and grain filling stages considerably reduced grain yield. Decrease in grain yield under drought stress condition may be due to the reduction in the duration and rate of grain filling processes which resulted in the production of small grains and consequently reducing grain yield. Machado et al. (1993) indicated that drought stress at near anthesis and grain filling stage decreased translocation of photosynthetic products, and resulted in wrinkled grains which decreased grain yield. In present study combined application of SA and adequate amount of $\mathrm{K}$ improved plant growth and grain yield of wheat greater than when SA and $\mathrm{K}$ were applied separately. $\mathrm{K}$ plays a vital role in plant growth and productivity by regulating photosynthesis, stomatal opening, and transportation of assimilates from source to sink, enzyme activity and carbohydrate synthesis (Daniel et al. 2016; Yawson et al. 2011; Lakudzala 2013). SA is also essential for plant growth, physiological performance and crop productivity under abiotic stress conditions. It can regulate transpiration rates, stomatal regulation and photosynthetic processes, and ion uptake and transport in plants (Gunes et al. 2005; War et al. 2011).

Starch is the most abundant component present in the grain endosperm of wheat (Lineback and Rasper, 1988). Grain starch was remarkably reduced under drought stress condition. This reduction may have been due to a reduction in plant photosynthetic activity, and therefore carbohydrate synthesis. Saeedipour (2011) reported that drought stress during anthesis and grain filling significantly reduced starch content of wheat. An adequate level of $\mathrm{K}$ fertilizer alleviates the adverse effects of drought and increases grain starch under both well-irrigated and drought stress conditions (Zareian et al. 2014; Fayez and Bazaid 2014). Application of SA in combination with $\mathrm{K}_{3}$, greatly enhanced grain starch content of wheat under well-irrigated and drought stress conditions. This increase in starch content, might be due to the combined effect of SA and K which regulated stomatal closure, improved photosynthetic activity, enhanced carbohydrate transportation from leaves to grains, and eventually resulted in a high grain starch content. Grain crude protein was increased under drought stress condition. Irrigation may decrease flour protein content by dilution of N with carbohydrates (Guttieri et al. 2005). Similarly, Singh et al. (2012) reported a significant increase in protein content of wheat grains grown under rainfed condition. An elevated level of $\mathrm{K}$ slightly increased crude protein under drought stress condition. Application of $\mathrm{K}$ improves plant $\mathrm{N}$ uptake and utilization, enzyme activity, and protein synthesis (Daniel et al. 2016; Lakudzala 2013). In present study, application of SA and $\mathrm{K}_{3}$ enhanced crude protein content in wheat under drought stress condition. Kumar et al. (1999) reported that SA treatment increased total protein in soybean grains, and this increase might be because of enhanced activity of nitrate reductase by SA application. Increase in grain protein content has a positive effect on nutritional and bread-making quality of wheat flour. Drought stress significantly increased grain total pentosan irrespective of SA acid and $\mathrm{K}$ treatments. $\mathrm{K}_{3}$ treatment slightly enhanced total pentosan content under drought stress condition. SA partially induced total pentosan content under 
well-irrigated condition. Effect of $\mathrm{K}$ fertilization and SA treatment on grain pentosans under drought stress condition, was not reported by earlier researchers. It is assumed that under drought stress, plants produced less number of fertile tillers, and most of this nonstarch polysaccharides might be accumulated in grains. Chunxi et al. (2002) indicated that ecological environment was a crucial factor for pentosan content in wheat. Rakszegi et al. (2014) found that the content of arabinoxylan was generally increased by drought stress in drought sensitive varieties of wheat. The present study indicated that water-soluble pentosan content was slightly lower under drought stress condition, particularly with $\mathrm{K}_{1}$ treated plants. Water-soluble pentosan increases the viscosity and the stability of dough foam structure. It helps in bigger loaf volume and a finer homogeneous bread crumb (Courtin and Delcour 2002). It was observed in present study that combined application of SA and a high dose of $\mathrm{K}$ fertilizer ( $\mathrm{K}_{3}$ treatment) to some extent was enhanced carbohydrate formation, and consequently, increased grain water-soluble pentosan content under drought stress condition.

Phy-P (myo-inositol 1,2,3,4,5,6-hexakis phosphate) serves as seed storage for phosphorus, but this compound can contribute to the nutritional deficiencies when seeds are used as food (Rosa 1999; Raboy 2001). It binds with proteins and important minerals such as $\mathrm{Fe}, \mathrm{Ca}$ and $\mathrm{Zn}$, and reduces their availability (Raboy 2001) Phy-P content was increased with higher $\mathrm{K}$ fertilization and drought stress condition. Application of SA did not affect grain Phy-P content under drought stress condition, but interestingly, the percentage of Phy-P to total P content was reduced by SA application. In present study, the decrease in the percentage of Phy-P to total P content may explain the increase of Pi content under combined SA and $\mathrm{K}_{3}$ treatments. Thus, from present study, it was found that combined $\mathrm{K}$ and SA application may decrease the share of total P in Phy-P, and increases bioavailability of Pi that may improve the grain nutritional quality.

Grain mineral content was affected by drought stress significantly. In present study K, $\mathrm{N}, \mathrm{P}, \mathrm{Pi}, \mathrm{Ca} \mathrm{Mg}$, and $\mathrm{Zn}$ contents increased under drought stress condition. Except for $\mathrm{Zn}$, this increase was greater in SA-treated plants where a high dose of $\mathrm{K}$ fertilizer $\left(\mathrm{K}_{3}\right.$ treatment) was also applied. SA and $\mathrm{K}$ levels had no effect on $\mathrm{Zn}$ content under drought stress condition. Combined application of SA and $\mathrm{K}_{3}$ treatment significantly increased grain $\mathrm{K}$, $\mathrm{N}$ and Ca contents. Plant growth was reduced in drought stressed plants, and thus minerals might have been transported from older leaves to the meristematic tissues and developing grains. Raza et al. (2013) found that application of K improved the uptake of K, N, $\mathrm{P}$ and $\mathrm{Ca}$ in wheat under drought stress condition. Application of SA increased minerals contents in wheat under drought stress condition, and combined application of SA and a high dose of $\mathrm{K}$ fertilizer ( $\mathrm{K}_{3}$ treatment) significantly increased grain $\mathrm{K}, \mathrm{N}$ and $\mathrm{Ca}$ contents. This increase in $\mathrm{K}, \mathrm{N}$ and $\mathrm{Ca}$ contents in wheat might be linked with drought mitigating effects of SA treatment. SA regulates ion uptake in plants, and it was observed that application of SA increased $\mathrm{K}, \mathrm{N}, \mathrm{P}$ and $\mathrm{Mg}$ content in maize under drought condition (Gunes et al. 2005). Alam (1994) revealed that drought stress increased N content in plants, and this increase was due to the accumulation of free amino acids that are not synthesized into protein. Patel and Singh (1998) also observed that under drought stress condition, most of the $\mathrm{N}$ and $\mathrm{P}$ was accumulated in grains. A higher of grain minerals 
contents particularly N, K, Ca and Pi may improve the nutritional quality of bakery products specially, the bread which is consumed largely in developing countries. In present study, it was found that grain Pi content slightly increased under drought stress condition, and SA application resulted in a higher value of grain Pi content. There has been insufficient research work on effect of drought, and combined treatment of SA and K on grain $\mathrm{Pi}$ content but overall, a positive relation was observed between total $\mathrm{P}$ and Pi content in this study, which could be a reason for a relatively higher grain Pi content in SA applied plants.

As a conclusion, drought stress significantly reduces grain yield and starch content, and increases antinutrient phytate $\mathrm{P}$ content in wheat. Application of a proper level of $\mathrm{K}$ and SA reduces the negative effects of drought stress and consequently improves wheat yield, grain minerals contents, grain starch content, crude protein content, and content of pentosans. Application of SA alone had no considerable influence on phytate $\mathrm{P}$ content of wheat. In general, the combined application of SA and appropriate levels of K can ameliorate the adverse effects of post anthesis drought stress, improves wheat productivity, and partially enhances grain minerals content, and nutritional quality.

\section{References}

Ahmad, P., Ashraf M., Hakeem, K.R., Azooz, M.M., Rasool, S., Chandna, R., Akram, N.A. 2014. Potassium starvation-induced oxidative stress and antioxidant defense responses in Brassica juncea. J. Plant Inter. 9:1-9.

Alam, S.M. 1994. Nutrient uptake by plants under stress conditions. In: M. Pessarakli (ed), Handbook of Plant and Crop Stress. Marcel Dekker, New York pp. 285-313.

Arfan, M., H.R. Athar, Ashraf, M. 2007. Does exogenous application of salicylic acid through the rooting medium modulate growth and photosynthetic capacity in two differently adapted spring wheat cultivars under salt stress? J. Plant Physiol. 6:685-694.

Ashraf, M.Y. 1998. Yield and yield components response of wheat (Triticum aestivum L.) genotypes tinder different soil water deficit conditions. Acta Agron. Hung. 46:45-51.

Buksa, K., Nowotna, A., Praznik, W., Gambus, H., Ziobro, R., Krawontka J. 2010. The role of pentosans and starch in baking of wholemeal rye bread. Food Res. 43:2045-2051.

Chen, P.S., Toribara, T.Y., Warner, H. 1956. Microdetermination of phosphorus. Anal Chem. 28:1756-1756.

Chunxi, L., Qiu Zongbo, Jiang Lina, Xia Z. 2002. Research on content of pentosan in wheat grain in different ecological environment. Acta Agric. Bor. Sin. 17:1-4.

Courtin, C.M., Delcour, J.A. 2002. Arabinoxylans and endoxylanases in wheat flour bread-making. J. Cereal Sci. 35:225-243.

Daniel, E.K., Carl J. Rose, John Lamb A. 2016. Potassium for crop production. University of Minnesota Extension. Available at: https:/www.extension.umn.edu/ agriculture/nutrient-management/potassium/ potassium-for-crop-production/ (Accessed on August 28, 2016).

De La Guardia, M.D., Benlloch, M. 1980. Effects of potassium and gibberellic acid on stem growth of whole sunflower plants. Physiol. Plant. 49:443-448.

Egilla, J.N., Davies, F. T., Boutton, T. W. 2005. Drought stress influences leaf water content, photosynthesis, and water-use efficiency of Hibiscus rosa-sinensis at three potassium concentrations. Photosynthetica 43:135-140.

Erel, R., Yermiyahu, U., Ben-Gal, A., Dag, A., Shapira, O., Schwartz, A. 2015. Modification of non-stomatal limitation and photoprotection due to K and Na nutrition of olive trees. J. Plant Physiol. 177:1-10.

Fayez, K.A., Bazaid, S.A. 2014. Improving drought and salinity tolerance in barley by application of salicylic acid and potassium nitrate. J. Saudi Soc. Agri. Sci. 13:45-55. 
Fujihara, S., Sasaki, H., Aoyagi, Y., Sugahara, T. 2008. Nitrogen-to-protein conversion factors for some cereal products in Japan. J. Food Sci. 73:204-209.

Gondor, O.K., Janda, T., Soós, V., Pál, M., Majláth, I., Adak, M.K., Balázs, E., Szalai, G. 2016. Salicylic acid induction of flavonoid biosynthesis pathways in wheat varies by treatment. Front. Plant Sci. 7:1447. doi: 10.3389/fpls.2016.01447.

Gunes, A., Inal, A., Alpaslan, M., Cicek, N., Guneri, E., Eraslan, F., Guzelordu, T. 2005. Effects of exogenously applied salicylic acid on the induction of multiple stress tolerance and mineral nutrition in maize (Zea mays L.). Arch. Agron. Soil Sci. 51:687-695.

Guttieri, M.J., McLean, R., Stark, J. C., Souza, E. 2005. Managing irrigation and nitrogen fertility of hard spring wheats for optimum bread and noodle quality. Crop Sci. 45:2049-2059.

Hashimoto, S., Shogren, M.D., Pomeranz, Y. 1986. Cereal pentosans: Their estimation and significance. I. Pentosans in wheat and milled wheat products. Cereal chem. 64:30-34.

Horvath, E., Pál, M., Szalai, G., Páldi, E., Janda T. 2007. Exogenous 4 hydroxybenzoic acid and salicylic acid modulate the effect of short-term Drought and freezing stress on wheat plants. Biol. Plant. 51:480-487. doi: 10.1007/s10535-007-0101-1.

Jatav, K.S., Agarwal, R.M., Tomar, N.S., Tyagi, S.R. 2014. Nitrogen metabolism, growth and yield responses of wheat (Triticum aestivum L.) to restricted water supply and varying potassium treatments. J. Indian Bot. Soc. 93:177-189.

Khan, M.I.R., Fatma, M., Per, T.S., Anjum, N.A., Khan, N.A. 2015. Salicylic acid-induced abiotic stress tolerance and underlying mechanisms in plants. Front. Plant Sci. 6:462. doi:10.3389/fpls.2015.00462.

Kumar, P., Dube, S.D., Chauhan, V.S. 1999. Effect of salicylic acid on growth, development and some biochemical aspects of soybean (Glycine max L. Merrill). Indian J. Plant Physiol. 4:327-330.

Lakudzala, Dinah D. 2013. Potassium response in some Malawi soils. ILCPA 8:175-181.

Lineback, D.R., Rasper, V.F. 1988. Wheat, Chemistry and Technology St Paul, MN: AACC.

Machado, E.C., Lagoa, A., Ticelli, M. 1993. Source-sink relationships in wheat subjected to water stress during three productive stage. Braz. J. Plant Physiol. 5:145-150.

Morris, M.L., Byerlee, Blaid, A. 1991. Wheat and barley production in rainfed marginal environments of the developing world. part I of 1990-91 CIMMYT world wheat facts and trends: wheat and barley production in rainfed marginal in environment of the developing world. CIMMYT, Mexico, D.F.51.

Nag, A. 2016. Techniques in agricultural, Environmental and Food Engineering, $3^{\text {rd }}$ edition. PHI learning private limited, Delhi-110092, pp. 39-41.

Patel, A.L., Singh, J. 1998. Nutrient uptake and distribution in aerial part of wheat under water stress at different growth stages. Ann. Agri. Bio. Res. 3:5-8.

Raboy, V. 2001. Seeds for a better future: 'Low phytate' grains help to overcome malnutrition and reduce pollution. Trends Plant Sci. 6:458-462.

Raboy, V., Dickinson, D.B. 1984. Effect of phosphorus and zinc nutrition on soybean seed phytic acid and zinc. Plant Physiol. 75:1094-1098.

Rakszegi, M., Lovegrove, A., Balla, K., Lang, L., Bedo, Z., Veisz, O., Shewry, P.R. 2014. Effect of heat and drought stress on the structure and composition of arabinoxylan and $\beta$-glucan in wheat grain. Carbohydr. Polym. 15:557-565.

Raza, S., M.A., Saleem, M.F., Shah, G.M., Jamil, M., Khan, I.H. 2013. Potassium applied under drought improves physiological and nutrient uptake performances of wheat (Triticum aestivum L.). J. Soil Sci. Plant Nutr. 13:175-185.

Rosa, M., Estepa, G., Hernandez, E.G., Villanova, B.G. 1999. Phytic acid content in milled cereal products and breads. Food Res. Int. 32:217-221.

Saeedipour, S. 2011. Comparison of the drought stress responses of tolerant and sensitive wheat cultivars during grain filling: impact of invertase activity on carbon metabolism during kernel development. J. Agr. Sci. 3:32-44.

Sakhabutdinova, A.R., Fatkhutdinova, D.R., Bezrukova, M.V., Shakirova, F.M. 2003. Salicylic acid prevents the damaging action of stress factors on wheat plants. Bulg. J. Plant Physiol. 1:314-319. 
Shiferaw, B., M. Smale, H. J. Braun, E. Duveiller, M. Reynolds, Muricho G. 2013. Crops that feed the world 10. Past successes and future challenges to the role played by wheat in global food security. J. Food Sci. 5:291-317.

Singh, S., Gupta, A.K., Kaur, N. 2012. Influence of drought and sowing time on protein composition, antinutrients, and mineral contents of wheat. Scientific World J.2012,Article ID485751, doi:10.1100/2012/485751.

War, A.R., Paulraj, M.G., War, M.Y., Ignacimuthu, S. 2011. Role of salicylic acid in induction of plant defense system in chickpea (Cicer arietinum L.). Plant Signal Behav. 6:1787-1792.

Waseem, M., Athar, H.U.R., Ashraf, M. 2006. Effect of salicylic acid applied through rooting medium on drought tolerance of wheat. Pak. J. Bot. 38:1127-1136.

Yawson, D.O., Kwakye, P. K., Armah, F. A., Frimpong, K. A. 2011. The dynamics of potassium (K) in representative soil series of Ghana. ARPN J. Agric. Biol. Sci. 6:48-55.

Zareian, A., Sharif-Abad, H.H., Hamidi, A. 2014. Yield, yield components and some physiological traits of three wheat (Triticum aestivum L.) cultivars under drought stress and potassium foliar application treatments. Int. J. Biosci. 4:168-175.

Zhu, J.K. 2002. Salt and drought stress signal transduction in plants. Annu. Rev. Plant Biol. 53:247-273.

\section{Electronic Supplementary Material (ESM)}

Electronic Supplementary Material (ESM) associated with this article can be found at the website of CRC at https://akademiai.com/loi/0806

Electronic Supplementary Table S1. Effect of combined application of potassium and SA on grain yield, starch, crude protein total pentosan, water-soluble pentosan (WSP) and phytate P content of wheat under drought stress condition. Values are means $\pm \mathrm{SD}(\mathrm{n}=4)$ at $\mathrm{p} \leq 0.05$. For each column means followed by same letter are not significantly different

Electronic Supplementary Table S2. Effect of combined application of potassium and SA on grain minerals contents ( $\mathrm{g}^{-1}$ dry weight) of wheat under drought stress condition. Values are means $\pm \mathrm{SD}(\mathrm{n}=4)$ at $\mathrm{p} \leq 0.05$. For each column means followed by same letter are not significantly different 